\title{
Modelling kinetics of thermal degradation of colour in peach puree
}

\author{
I.M.L.B. Ávila, C.L.M. Silva *
}

Universidade Católica Portuguesa, Escola Superior de Biotecnologia, Rua Dr. António Bernardino de Almeida, 4200 Porto, Portugal

\begin{abstract}
Optimisation of thermal processes relies on adequate degradation kinetic models for food safety and quality. In order to use peach puree as a model food to further validate calculated optimal conditions, isothermal experiments, using peach puree, were performed between $110^{\circ} \mathrm{C}$ and $135^{\circ} \mathrm{C}$. Colour was quantified using the $L, a, b$ system. Two combinations of these parameters, $L a / b$ and Total Colour Difference (TCD), were used to evaluate the total colour change. A one-step non-linear regression was performed on all data using the Arrhenius model. The changes in the $L$ and $b$ values followed a first-order reaction with activation energies of $107 \pm 7$ and $109 \pm 8 \mathrm{~kJ} / \mathrm{mol}$, respectively. The fractional conversion model was applied to $a$, Lalb and TCD resulting in activation energies of $106 \pm 13,106 \pm 10$ and $119 \pm 9 \mathrm{~kJ} / \mathrm{mol}$, respectively. (C) 1999 Elsevier Science Ltd. All rights reserved.
\end{abstract}

Keywords: Peach puree; Colour degradation; Kinetics; Modelling; Model food

\section{Introduction}

Thermal treatment is one of the most important methods of food preservation (Lund, 1975). However, excessive heating produces considerable losses in the quality and particularly in the organoleptic properties of foods (Hayakawa \& Timbers, 1977). Kinetic models of thermal destruction are essential to design new processes assuming a safe food product and giving a maximum retention of quality factors (Lund, 1975; Teixeira, Dixon, Zahradnik \& Zinsmeister, 1969). Moreover, information available on reaction kinetics is still quite limited (Holdsworth, 1990).

The first quality impact by which the consumers take the decision to acquire a product is its visual appearance. The colour of products can be specified by three co-ordinates in the colour space which can be obtained directly with a tristimulus colorimeter. The $L, a$ and $b$ system is the more frequently used scale to measure the colour of food products (Francis \& Clydesdale, 1975). The $L$-value is a measure of the lightness, the $b$-value indicates the change of the colour from blue to yellow, and the $a$-value the change from green to red (Hutchings, 1994).

Changes in food colour can be associated with its previous heat treatment history. Various reactions such

\footnotetext{
${ }^{*}$ Corresponding author. Tel.: 00-351-2-5580058; fax: 00-321-2590351; e-mail: crislui@esb.ucp.pt
}

as pigment destruction (carotenoids and chlorophylls) and non-enzymatic browning (Maillard) reactions, can occur during heating of fruits and vegetables and therefore affect its colour (Reyes \& Luh, 1960; Abets \& Wrolstad, 1979; Resnik \& Chirife, 1979; Cornwell \& Wrolstad, 1981). The retention of total colour can be used as a quality indicator to evaluate the extent of deterioration due to thermal processing (Shin \& Bhowmik, 1995). Several researchers have published work on modelling of thermal degradation kinetics of colour in the temperature range of sterilisation conditions. Silva and Ignatiadis (1995) presented a literature review on this subject. Table 1 reviews kinetic data on colour thermal degradation of some fruits and vegetables. The majority of the published work report first order or zero order degradation reaction kinetics. Only Steet and Tong (1996) described the thermal degradation kinetics of green colour in peas, applying the fractional conversion model (also known as reversible first order model Levenspiel, 1972).

The palatability and quality of fresh peach products depends on the variety and maturity index of the fruit itself (Delwiche \& Baumgardner, 1985). The processing of peach fruits to pulp, nectar, compote or to dried products is commercially established. The processing method is also very important because it can hardly damage peach colour, flavour, and texture (Askar, Abdel-Fadeel, Ghonaim, Abd El-Gaied \& Ali, 1996a,b). Some works have been published about the use of colour 


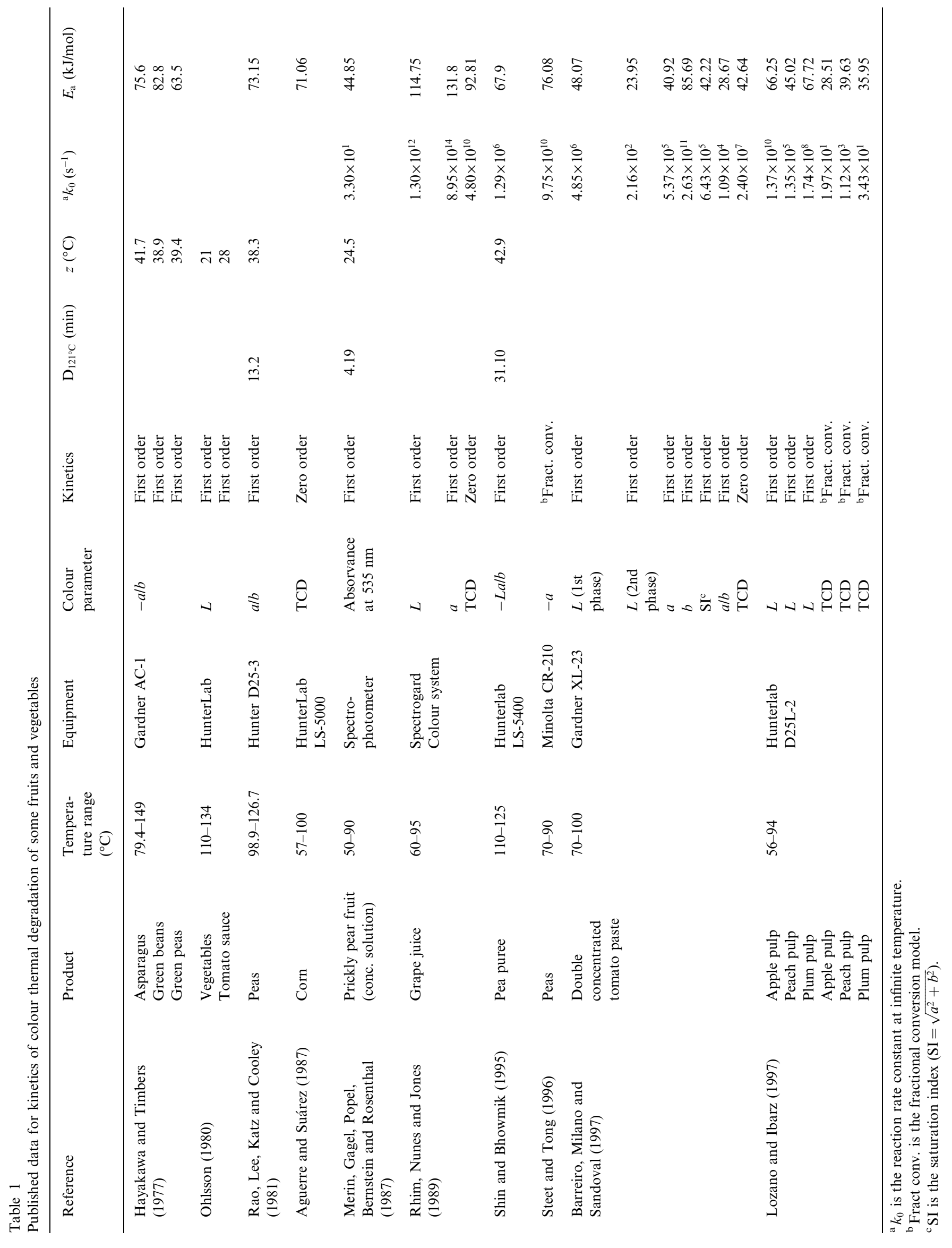


measurement of peaches to evaluate their maturity indexes (Delwiche \& Baumgardner, 1983, 1985) or on the quality control for canned peach halves (Duran, Rodrigo \& Alcedo, 1979), peach compote, pulp and nectar (Askar et al., 1996b).

The $\mathrm{pH}$ value of peach puree is in the range of 3.6-4.0 (Lund, 1976). Therefore, a relatively mild thermal treatment, such as pasteurisation, is adequate to stabilise it at room temperature (Fellows, 1988). Colour thermal degradation of apples, peaches and plums pulp was studied by Lozano and Ibarz (1997) in the temperature range of 56-94. However, due to its easy availability and sensitivity to heat treatment, this product has great potential to be used as a quality indicator for sterilisation processing conditions. At these processing temperatures (over $100^{\circ} \mathrm{C}$ ) peaches can only be used as a model food product.

Therefore, the objective of this research study was the mathematical modelling of colour peach puree thermal degradation kinetics, in order to apply it as an indicator for sterilisation thermal processing conditions impact on quality.

\section{Kinetic considerations}

Numerous research studies apply zero- (Eq. (1)) or first-order (Eq. (2)) models to describe the degradation of colour in food products:

$C=C_{0}-k t$,

$C=C_{0} \exp (-k t)$

where $C$ is the measured colour scale value, or a combination of the colour scale values, $C_{0}$ the initial $C, t$ the heating time and $k$ the reaction rate constant.

Also the fractional conversion model can be used to describe the colour degradation (Levenspiel, 1972):

$\frac{C-C_{\mathrm{f}}}{C_{0}-C_{\mathrm{f}}}=\exp (-k t)$,

where $C_{\mathrm{f}}$ is the final equilibrium value of the colour parameter.

Colour concentration can be translated in the $L, a$ and $b$ parameters of the colour system, or by a combination of these three values, such as Lalb and TCD:

$\mathrm{TCD}=\sqrt{\Delta L^{2}+\Delta b^{2}+\Delta a^{2}}$.

$L a / b$ and TCD express a total colour change of the food product (Shin \& Bhowmik, 1995).

The Arrhenius equation is usually applied to evaluate the reaction rate constant temperature dependence:

$k=k_{\mathrm{ref}} \exp \left[-\frac{E_{\mathrm{a}}}{R}\left(\frac{1}{T}-\frac{1}{T_{\mathrm{ref}}}\right)\right]$, where $T$ is the absolute temperature, $T_{\text {ref }}$ the reference absolute temperature, $k_{\text {ref }}$ the reaction rate constant at the reference temperature, $E_{\mathrm{a}}$ the activation energy and $R$ the universal gas constant.

\section{Materials and methods}

Peaches of the Roubidoux cultivar were purchased in the local market, peeled, destoned and pureed. After being homogenised with a spoon, the peach puree was separated into small dark plastic bags and frozen stored at $-20 \pm 1{ }^{\circ} \mathrm{C}$.

For each experiment, the required amount of peach puree was thawed at ambient temperature and introduced into glass vials (Chrompack/Cat. ${ }^{\circ} 10202 /$ Vial 2 $\mathrm{ml}$ ) which were closed and kept out of daylight. These small vials were used to reduce the existence of sample temperature gradient during heating.

Six isothermal experiments were performed at $110^{\circ} \mathrm{C}$, $115^{\circ} \mathrm{C}, 120^{\circ} \mathrm{C}, 125^{\circ} \mathrm{C}, 130^{\circ} \mathrm{C}$ and $135^{\circ} \mathrm{C}$ in an oil bath (Tempunit TU-16D Techne) with temperature control. The vials were placed in the oil bath after its temperature had reached the specified value. At pre-specified time intervals, the samples were cooled in an ice-water mixture immediately after withdrawal from the oil bath. After cooling the samples, the colour measurements were carried out in a room with controlled light. A Petri dish (normax $60 \times 15 \mathrm{~mm}$ ) was filled with the puree contained in four vials $(\approx 12 \mathrm{~g})$ and placed directly over the Colorimeter (Minolta Chroma Meter Cr-300). The $L, a$ and $b$ colour system was used to evaluate the colour.

Statistical analysis of the data was performed using the STATA program version 4.0 (Stata Corporation, 1995). Both two-step and one-step non-linear regressions (Arabshahi \& Lund, 1985) were performed and also regression analysis of residuals was examined (Box, Hunter \& Hunter, 1978).

\section{Results and discussion}

With the increase of heating temperature and time, peach puree becomes darker. This corresponds to a decrease in the $L$-value of the colour scale (Fig. 1). Peach puree also loses its yellowness and becomes more red when heated. This change is translated by a decrease of the $b$-value (Fig. 2) and an increase of the $a$-value (Fig. 3).

Enzymatic browning is a serious problem when dealing with peaches because the oxidative enzymes, such as peroxidase and polyphenolase, may cause browning accompanied by changes in colour, flavour and nutritive value during frozen storage and thawing of the product (Reyes \& Luh, 1960). During the thermal 


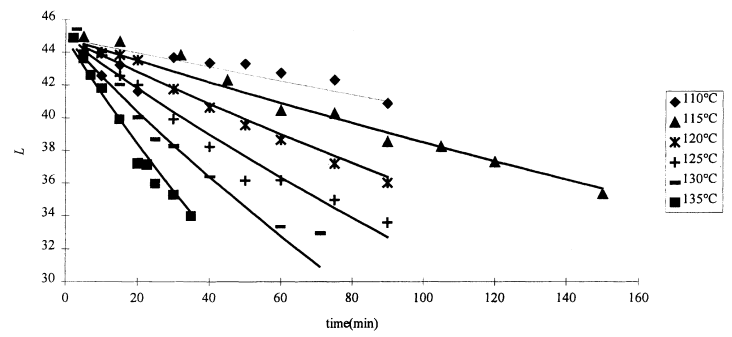

Fig. 1. Thermal degradation of the $L$-value colour parameter as a function of time and temperature (experimental and model predicted values).

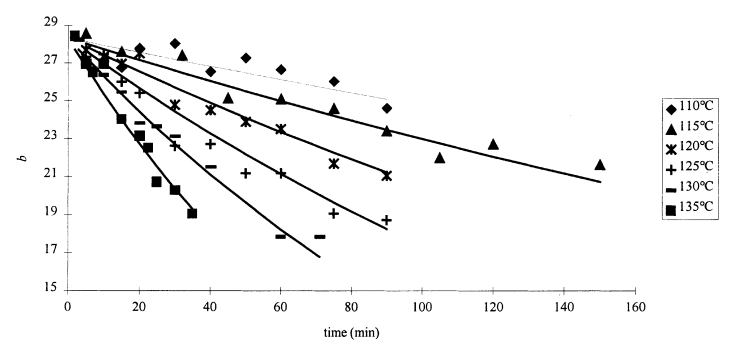

Fig. 2. Thermal degradation of the $b$-value colour parameter as a function of time and temperature (experimental and model predicted values).

treatment of peaches, those enzymes are inactivated, but many other reactions can take place affecting colour. Carotenoids degradation and non-enzymatic browning (Maillard) reactions are the most common.

In order to find the kinetic model that better fits the obtained experimental data points, the two-step method was used as a first approach (Arabshahi \& Lund, 1985). Considering each colour parameter, a regression analysis was applied, in a first step, for each isothermal experiment to calculate the corresponding reaction rate constant. Figs. 1 and 2 show the first order reaction model (Eq. (2)) applied to the $L$ and $b$ values, respectively. The fractional conversion kinetics (Eq. (3)) was used to model the thermal degradation of the $a, L a / b$ and TCD parameters (Figs. 3-5, respectively). In the second step, the Arrhenius equation (5) was used to

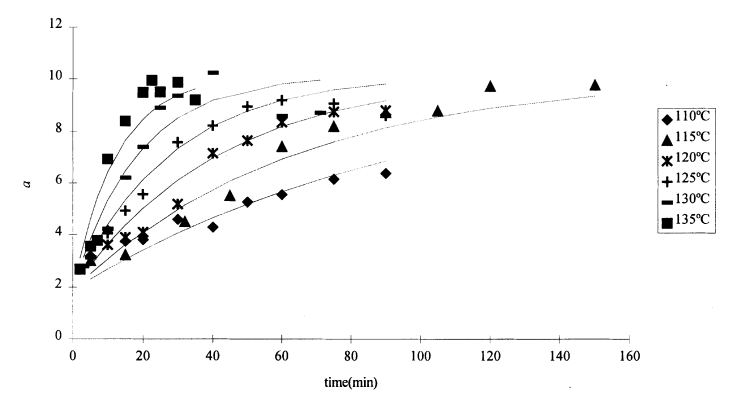

Fig. 3. Thermal degradation of the $a$-value colour parameter as a function of time and temperature (experimental and model predicted values).

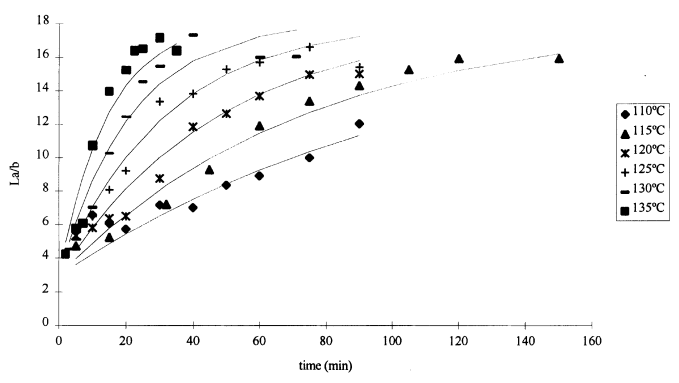

Fig. 4. Thermal degradation of the total colour change parameter, $L a / b$, as a function of time and temperature (experimental and model predicted values).

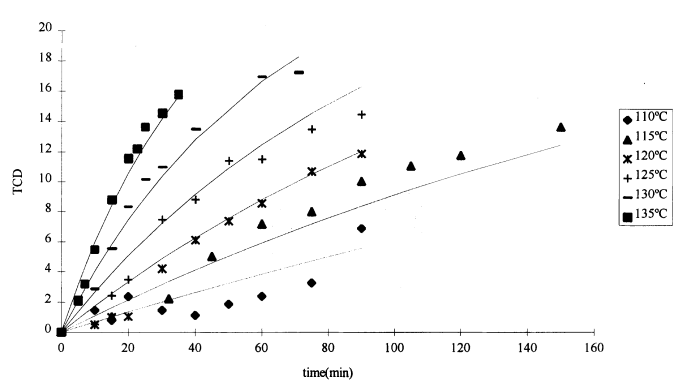

Fig. 5. Thermal degradation of TCD as a function of time and temperature (experimental and model predicted values).

describe the temperature dependence of the reaction rate constant.

In order to make a better estimate of the kinetic parameters, a one-step non-linear regression was applied to all data (Arabshahi \& Lund, 1985). Based on the examination of the residuals, these proved to be the most adequate models, once the distribution of residuals has no visual tendency (were randomly distributed around zero). One example of these plots is showed in Fig. 6 for the Lalb parameter.

Estimated activation energies and rate constants at the reference temperature of $122.5^{\circ} \mathrm{C}$ and corresponding $95 \%$ confidence intervals are reported in Table 2. These values are within those published in the literature.

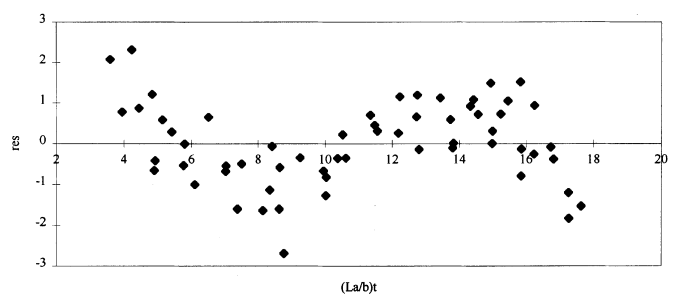

Fig. 6. Plot of residuals for the $L a / b$ parameter regression analysis as a function of the predicted value, $(L a / b) t$. 
Table 2

Kinetic parameters, for the colour degradation of peach puree, estimated using the one-step non-linear regression method

\begin{tabular}{llllll}
\hline & $E_{\mathrm{a}}(\mathrm{kJ} / \mathrm{mol})$ & $k_{122.5^{\circ} \mathrm{C}}\left(\mathrm{min}^{-1}\right)$ & $C_{0}$ & $C_{\mathrm{f}}$ & $R^{2}$ \\
\hline$L$ & $107 \pm 7$ & $2.9 \times 10^{-3} \pm 2 \times 10^{-4}$ & $44.8 \pm 0.4$ & - & 0.999 \\
$b$ & $109 \pm 8$ & $4.0 \times 10^{-3} \pm 3 \times 10^{-4}$ & $28.3 \pm 0.3$ & - & 0.999 \\
$a$ & $106 \pm 13$ & $0.03 \pm 8 \times 10^{-3}$ & $1.9 \pm 0.6$ & $10.1 \pm 0.8$ & 0.990 \\
Lalb & $106 \pm 10$ & $0.026 \pm 6 \times 10^{-3}$ & $2.9 \pm 0.8$ & $18.2 \pm 1.3$ & 0.993 \\
TCD & $119 \pm 9$ & $0.0085 \pm 3 \times 10^{-3}$ & 0 & $26 \pm 6$ & 0.986 \\
\hline
\end{tabular}

\section{Conclusions}

The objective measurement of colour using the $L, a$ and $b$ system can totally translate the real behaviour of canned peach puree when submitted to heat treatment. The $L a / b$ and TCD parameters proved to be good indicators of the total colour change of heat treated peach puree.

The Arrhenius model described well the temperature dependence of the reaction rate constant for all the colour parameters considered. The peach puree colour thermal degradation followed a first-order reaction kinetics for the $L$ and $b$ values with activation energies of $107 \pm 7$ and $109 \pm 8 \mathrm{KJ} / \mathrm{mol}$, and rate constants at reference temperature $\left(122.5^{\circ} \mathrm{C}\right)$ of $2.9 \times 10^{-3} \pm 2 \times 10^{-4}$ and $4 \times 10^{-3} \pm 3 \times 10^{-4} \mathrm{~min}^{-1}$, respectively. The $a, L a / b$ and TCD parameters were modelled using the fractional conversion equation. The activation energies obtained were $106 \pm 13,106 \pm 10$ and $119 \pm 9 \mathrm{~kJ} / \mathrm{mol}$, and the reaction rate constants at reference temperature of $122.5^{\circ} \mathrm{C}$ were $0.03 \pm 8 \times 10^{-3}, 0.026 \pm 6 \times 10^{-3}$ and $0.0085 \pm 3 \times 10^{-3} \mathrm{~min}^{-1}$, respectively. Therefore, retention of peach puree total colour may be used as a quality indicator for sterilisation processing conditions.

\section{Acknowledgements}

The author Isabel M.L.B. Ávila acknowledges the financial support from FLAD (Fundação Luso-Americana para o Desenvolvimento) to participate and present part of this paper's contents in the IFT Annual Meeting 1996 (New Orleans, USA). The authors also wish to thank Teresa Saez for her help in performing the experimental work.

\section{References}

Abets, J. E., \& Wrolstad, R. E. (1979). Causative factors of colour deterioration in strawberry preserves during processing and storage. Journal of Food Science, 44, 75-78.

Arabshahi, A., \& Lund, D. B. (1985). Considerations in calculating kinetic parameters from experimental data. Journal of Food Process Engineering, 7, 239-251.
Aguerre, R. J., \& Suárez, C. (1987). Kinetics of colour change in corn: effect of temperature and moisture content. Lebensmittel Wissenshaft und Technologie, 20(6), 287-290.

Askar, A., Abdel-Fadeel, M. G., Ghonaim, M., Abd El-Gaied, I. O., \& Ali, A. M. (1996a). Chemical and technological studies on canned peach fruit (compote). Fruit Processing, 1, 21-24.

Askar, A., Abdel-Fadeel, M. G., Ghonaim, M., Abd El-Gaied, I. O., \& Ali, A. M. (1996b). Quality assurance of peach pulp and nectar. Fruit Processing, 4, 151-155.

Barreiro, J. A., Milano, M., \& Sandoval, A. J. (1997). Kinetics of colour change of double concentrated tomato paste during thermal treatment. Journal of Food Engineering, 33, 359-371.

Box, G. E. P., Hunter, W. G., \& Hunter, J. S. (1978). Statistics for Experimenters. New York: Wiley.

Cornwell, C. J., \& Wrolstad, R. E. (1981). Causes of browning in pear juice concentrate during storage. Journal of Food Science, 46, 515518.

Delwiche, M. J., \& Baumgardner, R. A. (1983). Ground colour measurements of peach. Journal of the American Society for Horticultural Science, 108(6), 1012-1016.

Delwiche, M. J., \& Baumgardner, R. A. (1985). Ground colour as a peach maturity index. Journal of the American Society for Horticultural Science, 110(1), 53-57.

Duran, L., Rodrigo, M., \& Alcedo, M. J. (1979). Measurement of colour of canned peaches. Confructa, 24(1/2), 13-27.

Fellows, P. (1988). Food processing technology. Chichester: Elis Horwood.

Francis, F. J., \& Clydesdale, F. H. (1975). Food colorimetry: theory and applications (pp. 130-142). Westport, CT: AVI Publishing.

Hayakawa, K., \& Timbers, G. E. (1977). Influence of heat treatment on the quality of vegetables: changes in visual green colour. Journal of Food Science, 42(3), 778-781.

Holdsworth, S. D. (1990). Kinetic data - What is available and what is necessary. In R.W. Field, \& J.A. Howell, Processing and quality of foods. 1 HTST processing (pp 74-78). London: Elsevier.

Hutchings, J. B. (1994). Food colour and appearance. London: Blackie Academic and Professional.

Levenspiel, O. (1972). Interpretation of batch reactor data. In Chemical Reaction Engineering (2nd ed., pp. 41-47). New York: Wiley.

Lozano, J. E., \& Ibarz, A. (1997). Colour changes in concentrated fruit pulp during heating at high temperatures. Journal of Food Engineering, 31, 365-373.

Lund, D. B. (1975). Effects of blanching, pasteurisation, and sterilisation on nutrients. In R.S. Harris, \& E. Karmas, Nutritional evaluation of food processing (pp. 205-240). New York: AVI Publishing.

Lund, D. B. (1976). Heat processing. In M. Karel, D.B. Lund, \& O.R. Fennema, Principles of food science. Part II. Physical principles of food preservation, (ch. 3, pp. 32-35). New York: Marcel Dekker.

Merin, U., Gagel, S., Popel, G., Bernstein, S., \& Rosenthal, I. (1987). Thermal degradation kinetics of pickly-pear-fruit red pigment. Journal of Food Science, 52(2), 485-486. 
Ohlsson, T. (1980). Temperature dependence of sensory quality changes during thermal processing. Journal of Food Science, 45, 836-839.

Rao, M. A., Lee, C. Y., Katz, J., \& Cooley, H. J. (1981). A kinetic study of the loss of vitamin C, colour and firmness during thermal processing of canned peas. Journal of Food Science, 46, 636-637.

Resnik, S., \& Chirife, J. (1979). Effect of moisture content and temperature on some aspects of non-enzymatic browning in dehydrated apple. Journal of Food Science, 44, 601-605.

Reyes, P., \& Luh, B. S. (1960). Characteristics of browning enzymes in Fay Elberta freestone peaches. Food Technology, 14, 570-575.

Rhim, J. N., Nunes, R. V., \& Jones, V. A. (1989). Kinetics of colour change of grape juice generated using linearly increasing temperature. Journal of Food Science, 54(3), 776-777.
Shin, S., \& Bhowmik, S. R. (1995). Thermal kinetics of colour changes in pea puree. Journal of Food Engineering, 24, 77-86.

Silva, C. L. M., \& Ignatiadis, P. (1995) Modelling food colour degradation kinetics - A review. Proceedings of the first main meeting of the concerted action CIPA (CT94-0195, pp. 76-81).

Stata Corporation (1995). Stata Statistical Software: Release 4.0 college station.

Steet, J. A., \& Tong, C. H. (1996). Degradation kinetics of green colour and chlorophylls in peas by colorimetry and HPLC. Journal of Food Science, 61(5), 924-931.

Teixeira, A. A., Dixon, J. R., Zahradnik, J. W., \& Zinsmeister, G. E. (1969). Computer optimisation of nutrient retention in the thermal processing of conduction-heated foods. Food Technology, 23(6), $137-142$. 